\title{
Correction: Yes and Lyn play a role in nuclear translocation of the epidermal growth factor receptor
}

\author{
M. lida ${ }^{1}$ T. M. Brand ${ }^{1} \cdot$ D. A. Campbell ${ }^{1}$ C. Li ${ }^{1} \cdot$ D. L. Wheeler ${ }^{1}$
}

Published online: 5 December 2018

(c) Springer Nature Limited 2018

Correction to: Oncogene https://doi.org/10.1038/onc.2012. 90; published online 19 March 2012.

In Figure 4C, it was identified that the Histone H3 and $\alpha$-Tubulin purification control blots for YES and LYN overexpressing cells were duplicated. The original Histone
H3 control blot was found and confirmed the published results; however, the $\alpha$-Tubulin control blot was not found. This error was determined to not impact the scientific findings of this figure. The authors regret this error.
These authors contributed equally: M. Iida, T. M. Brand

The original article can be found online at https://doi.org/10.1038/onc. 2012.90 .

D. L. Wheeler

dlwheeler@wisc.edu

1 Department of Human Oncology, University of Wisconsin School of Medicine and Public Health, Madison, WI, USA 